\title{
GMR
}

\section{Screening and identification of cucumber germplasm and rootstock resistance against the root-knot nematode (Meloidogyne incognita)}

\author{
X.Z. Li and S.X. Chen \\ College of Horticulture Science, Northwest A \& F University, \\ Key Laboratory of Horticultural Plant Germplasm Resources Utilization in \\ Northwest Yangling Shaanxi, China \\ Corresponding author: S.X. Chen \\ E-mail: shuxiachen@nwsuaf.edu.cn
}

Genet. Mol. Res. 16 (2): gmr16029383

Received September 28, 2016

Accepted February 23, 2017

Published April 13, 2017

DOI http://dx.doi.org/10.4238/gmr16029383

Copyright (C) 2017 The Authors. This is an open-access article distributed under the terms of the Creative Commons Attribution ShareAlike (CC BY-SA) 4.0 License.

\begin{abstract}
Root-knot nematodes (Meloidogyne spp) are destructive agricultural pests that reduce the productivity of cultivated vegetables worldwide, especially when vegetables are cropped continuously in greenhouses. Cucumbers (Cucumis sativus L.), in particular, suffer extensive damage due to root-knot nematodes, and only a few wild species are known to be resistant. Grafting of cultivated plants to rootstocks of known resistant germplasms could be an effective method to resolve this problem. In this study, 21 cucumber germplasms and seven rootstocks were evaluated for resistance based on the growth of cucumber seedlings and resistance indexes to Meloidogyne incognita, which were surveyed 25 days after inoculation with $M$. incognita. Cluster analysis and principal component analysis (PCA) were used to investigate the resistance of 21 cucumber germplasms and seven rootstocks based on their growth and resistance indexes after inoculation with $M$. incognita. These analyses showed that the 21 germplasms and seven rootstocks could be divided into three groups based upon
\end{abstract}

Genetics and Molecular Research 16 (2): gmr16029383 
their resistance levels: moderately resistant, susceptible, and highly susceptible to $M$. incognita. All 21 cucumber germplasms exhibited susceptibility or high susceptibility to $M$. incognita and most rootstocks exhibited moderate resistance. The PCA results were consistent with those of the clustering analysis. The Jinyou No.1 cultivar had the highest resistance to $M$. incognita among the 21 cucumber germplasms, and Huangzhen No.1 cultivar had the highest resistance among the seven rootstock cultivars.

Key words: Cucumber; Rootstock; Root-knot nematodes; Resistance identification; Clustering analysis; Principal component analysis

\section{INTRODUCTION}

Cucumber (Cucumis sativus L.) is an important vegetable worldwide and is the second most popular crop planted in greenhouses (Sebastian et al., 2010; Mao et al., 2016). In China, cucumber has been cultivated for at least 3000 years, with cultivated acreage in 2012 estimated at 240,000 ha (Lv et al., 2012). As the result of continuous cropping over many years, the severity of root-knot nematode infestation has increased, especially when cucumbers are cropped in greenhouses (Huang et al., 2016). Meloidogyne incognita is the most common root-knot nematode species in Shaanxi province (Zhang et al., 2011; Liu et al., 2014). Surveys conducted by Dong et al. (2003) showed that approximately $67.6 \%$ of greenhouses contained plants infested with root-knot nematodes, with $95 \%$ of greenhouses containing crops over 4-years-old suffering from infestation. M. incognita infestation has important effects on the growth of cucumber roots and causes the formation of root galls, yellowed and stunted leaves, and even the destruction of whole plants (Pandey et al., 2003; Escobar et al., 2015). In addition, infestation by M. incognita also increases the occurrence of soil-borne diseases such as Fusarium wilt (Wang and Roberts, 2006). These issues result in severe damage to the yield and quality of vegetables (Echeverrigaray et al., 2010; Huang et al., 2014; Qiao et al., 2014).

Researchers have attempted to identify cultivated cucumber resources with resistance to M. incognita (Ye et al., 2011; Ma et al., 2014). Winstead and Sasser (1956) discovered that all 50 of their cucumber varieties were resistant to $M$. hapla, but were susceptible to $M$. incognita and M. javanica. Fassuliotis and Rau (1963) evaluated cucumber germplasm from the US Department of Agriculture, none of which exhibited resistance to M. incognita. For many years after these studies, researchers were unable to identify any cucumber materials with resistance to M. incognita (Walters and Wehner, 1997; Jia and Wu, 2011). However, several wild species that are highly resistant to $M$. incognita have been reported in recent years, such as $C$. metuliferus Naud., C. heptadactylus Naud., C. longipes Hook, and C. hystrix Chakr (Chen et al., 2001; Shen et al., 2007; Ma et al., 2014).

Owing to the lack of cucumber germplasm identified with resistance to $M$. incognita, chemical nematicides have now become the major means of controlling root-knot nematodes (Li et al., 2013; Xi et al., 2013). However, the chemical nematicides used have severely polluted the soil and aroused substantial public concern about food safety, especially considering that cucumbers are mostly eaten fresh. Unfortunately, wild species have always been difficult to crossbreed with cultivated varieties; therefore, wild resistant species have been used as

Genetics and Molecular Research 16 (2): gmr16029383 
rootstocks for grafting as an effective method to impart the disease resistance of the resistant varieties to the cultivated varieties (Li et al., 2014; Ma et al., 2014; Wang et al., 2014; Liu et al., 2015). Liu et al. (2015) screened the resistance of 53 wild cucumber germplasms to nematodes and selected a Meloidogyne incognita-resistant rootstock suitable for cucumber, melon, and watermelon scions. Subsequently, Wang et al. (2013) collected 20 national and international cucumber rootstocks to evaluate their capacity for resistance to $M$. incognita. Those authors found that Figleaf gourd, Kurotane, and Eibulu plants had stronger capacity for resistance.

Currently, various species of cucumber and cucumber rootstock are used in production. Their ability to resist root-knot nematode lacks systematic evaluation. Previously, the resistance of vegetables to root-knot nematodes has been compared using disease index (Huo et al., 2008). However, a single evaluation index is often not accurate enough, and there is a need for the comprehensive consideration of multi-indicators (Wang et al., 2013). In this study, 21 cucumber germplasms and seven rootstock cultivars that are widely used for production were collected and their resistance to nematodes was evaluated using a multiple evaluation index. The results indicate that cucumber germplasm and rootstock cultivars had high diversity in terms of resistance to $M$. incognita, and are expected to provide the basis for further application in production.

\section{MATERIAL AND METHODS}

\section{Source of root-knot nematodes}

The root-knot nematodes were collected from tomato roots that had obvious galls and were maintained using the susceptible tomato cultivar Dongfen No.3 in a greenhouse at 22$26^{\circ} \mathrm{C}$. The roots of tomato plants were chopped and sterilized with $0.5 \%$ sodium hypochlorite for $3 \mathrm{~min}$, and then rinsed with water. Root-knot nematode eggs were isolated from the tomato roots with water on a $25-\mu \mathrm{m}$ sieve. Eggs were subsequently collected and cultivated on a moist Petri dish containing distilled water at $28^{\circ} \mathrm{C}$ for $24 \mathrm{~h}$ to hatch second-stage juveniles (J2), which were then collected and used for species identification and plant inoculation.

\section{Preparation of plant material}

We used 14 cucumber cultivars, six inbred lines, one wild germplasm, and seven cucumber rootstocks in this study (Table 1). Seeds of all cultivars and inbred lines were washed in water at $55^{\circ} \mathrm{C}$ for $15 \mathrm{~min}$, and then cultivated at $28^{\circ} \mathrm{C}$ on wet filter paper in Petri dishes. Seeds prepared for germination were sown in autoclaved sand in $8 \times 8$-cm plastic pots, and watered with 1/4 Hoagland's nutrient solution twice weekly. All pots (one plant per pot) were arranged in an illumination incubator (RXZ-5COB-LED, Ningbo, Zhejiang, China) under the following cycle: $26^{\circ} \mathrm{C}$ and $14-\mathrm{h}$ light $/ 18^{\circ} \mathrm{C}$ and 10 -h darkness, with relative humidity maintained at $88 \%$.

\section{Identification of root-knot nematode}

Based on morphology, the root-knot nematodes were identified by Guanqu Zhang from the Nematode Research Group at the Plant Protection College. For PCR identification, mixed DNA was extracted from the hatched J2s using the method reported by Cenis (1993).

Genetics and Molecular Research 16 (2): gmr16029383 
Table 1. Twenty-eight germplasms used in this study.

\begin{tabular}{l|l|l|l|l|l}
\hline No. & Cultivar & Source of collection & No. & Cultivar & Source of collection \\
\hline 1 & No.14 & Yangling, Shaanxi & 15 & Lisha & Beijing \\
\hline 2 & No.26 & Yangling, Shaanxi & 16 & Zhongnong No.16 & Beijing \\
\hline 3 & Q $_{24}$ & Yangling, Shaanxi & 17 & Zhaibuwan & Jilin \\
\hline $\mathbf{5}$ & Q & Yangling, Shaanxi & 18 & Gaochanwang Yapajia & Jilin \\
\hline 6 & Q 16 & Yangling, Shaanxi & 19 & Yanziru & Jinzhou, Liaoning \\
\hline 7 & Commum CAT & Yangling, Shaanxi & 20 & Cuixiang No.6 & Zhuzhou, Hunan \\
\hline $\mathbf{8}$ & Jinyou No.1 & Tianjin & 21 & Liuyangbai & Hunan \\
\hline 10 & Jinchun No.4 & Tianjin & 22 & Qianglishi F1 & Shandong \\
\hline 11 & Jinchun No.5 & Tianjin & 23 & Ganfeng No.1 & Qingdao, Shandong \\
\hline 12 & Jinyan No.4 & Tianjin & 24 & Guozhen No.2 & Beijing \\
\hline 13 & Luyangxinsi & Shandong & 25 & Banzhen No.3 & Shouguang, Shandong \\
\hline 14 & Baisite No.8 & Guangzhou & 26 & Liangba & Shouguang, Shandong \\
\hline
\end{tabular}

PCR amplification was performed using specific primers as described by $\mathrm{Hu}$ et al. (2011). Specific primers were synthesized by Sangon Biotech (Shanghai, China) and are listed in Table 2. Of these, MF/MR were diagnostic primers designed based on 28S rRNA D2D3 of Meloidogyne nematodes. Mi-F/Mi-R, Me-F/Me-R, and Fjav/Rjav were diagnostic primers designed based on the alignment of ribosomal intergenic spacer 2 (IGS2) sequences of $M$. incognita, $M$. enterolobii, and $M$. javanica, respectively. The final volume of the PCR mixture was $20 \mu \mathrm{L}$, and included 60 ng DNA, $10 \mu \mathrm{L}$ Mix, $1 \mu \mathrm{L}$ forward and reverse primers, and 7 $\mu \mathrm{L} \mathrm{ddH}_{2} \mathrm{O}$. The PCR program was as follows: 4 min at $95^{\circ} \mathrm{C}$, followed by 35 cycles of $30 \mathrm{~s}$ at $94^{\circ} \mathrm{C}, 30 \mathrm{~s}$ at $60^{\circ} \mathrm{C}, 1 \mathrm{~min}$ at $72^{\circ} \mathrm{C}$, and $10 \mathrm{~min}$ at $72^{\circ} \mathrm{C}$. PCR products were stored at $4{ }^{\circ} \mathrm{C}$.

Table 2. Primers sequences used for root-knot nematode identification.

\begin{tabular}{l|l|l|l}
\hline Forward primer & Sequence $\left(5^{\prime}-3^{\prime}\right)$ & Reverse primer & Sequence $\left(5^{\prime}-3^{\prime}\right)$ \\
\hline MF & GGGGATGTTTGAGGCAGATTTG & MR & AACCGCTTCGGACTTCCACCAG \\
\hline Mi-F & GTGAGGATTCAGCTCCCCAG & Mi-R & ACGAGGAACATACTTCTCCGTCC \\
\hline Fjav & GGTGCGCGATTGAACTGAGC & Rjav & CAGGCCCTTCAGTGGAACTATAC \\
\hline Me-F & AACTTTTGTGAAAGTGCCGCTG & Me-R & TCAGTTCAGGCAGGATCAACC \\
\hline
\end{tabular}

PCR products were separated on $2 \%$ agarose gels and stained with Goldview (EB substation; Toyobo). A DS2000 DNA ladder (Dongsheng Biotech, Shanghai, China) was used to determine the molecular sizes of the bands. Band patterns were photographed under UV light using the Alphalmager (Alpha Innotech).

\section{Inoculation of cucumber and rootstock seedlings with the $\mathrm{J} 2$ of $M$. incognita}

The J2s were then re-suspended in sterile water, and the concentration was adjusted to $2000 \mathrm{~J} 2 / \mathrm{mL}$. The cucumber seedlings were inoculated with the $\mathrm{J} 2$ of $M$. incognita by pouring $1 \mathrm{~mL}$ of the nematode suspension into holes with a 2-cm depth around the bases of the plants when the first two true leaves of cucumber seedlings were spread completely. Cucumber seedlings inoculated with $1 \mathrm{~mL}$ water were used as controls. Ten seedlings for each germplasm were included in each experiment, and each experiment was repeated at least three times.

Genetics and Molecular Research 16 (2): gmr16029383 


\section{Measurement of growth and resistance indexes}

Twenty-five days after inoculation with $\mathrm{J} 2$ or water, the roots of all seedlings for all germplasms were gently washed and the following growth indexes were measured: plant height (PH), stem diameter (SD), aerial part fresh weight (APFW), root fresh weight (RFW), and total fresh weight (TFW). The growth indexes showed as the relative growth rate using the followed formulae:

$$
\text { Relative growth rate }=\frac{\text { the value of treatment }}{\text { the value of control }} \times 100 \%
$$

We also measured the following resistance indexes: gall number (GN), root infection percent (RIP; Mao, 2007), gall index (GI; Boiteux and Charchar, 1996), and disease index (DI; Li and Zhu, 2005).

RIP, GI, and DI were calculated using the following formulae:

$$
R I P=\frac{N i}{N} \times 100 \%
$$

Where, $N i$ is the number of roots infected by root-knot nematodes per seedling, and $N$ is the total number of roots per seedling.

$$
G I=\frac{N}{W}
$$

Where, $N$ is the number of galls per seedling, and $W$ is the RFW per seedling.

For DI, we first evaluated gall severity per seedling using the levels $0-5$, where $0=$ no gall, $1=1-2$ galls, $2=3-10$ galls, $3=11-30$ galls, $4=31-100$ galls, and $5{ }^{3} 100$ galls. We then used the following formula to calculate DI:

$$
D I=\frac{\sum S i \times N i}{N}
$$

Where, $S i$ is the level of gall severity, $N i$ is the number of seedlings belonging to the same level, $i$ pertains to the different levels, and $N$ is the number of seedlings. For DI, the resistance of germplasms to root-knot nematodes was classified using five levels, where $0=$ immune, $0-1.0=$ highly resistant, $1.0-2.0=$ resistant, $2.0-3.0=$ moderately resistant, $3.0-4.0=$ susceptible, and $>4.0=$ highly susceptible.

\section{Analysis of data for growth and resistance indexes}

A similarity matrix was generated based on simple matching coefficients. The similarity coefficient and genetic distance were analyzed according to the method described by Nei (1972). NTSYS-PC 2.2 software (Rohlf, 1998) was used to perform cluster analysis

Genetics and Molecular Research 16 (2): gmr16029383 
on resistance indexes in the similarity matrix, using the unweighted pair group method with arithmetic mean (UPGMA). PCA (IBM SPSS Inc., Chicago, IL, USA) was used to detect clustering and to summarize the characteristics of different cultivars inoculated with $M$. incognita. To eliminate the influence of dimension, data for agro-morphological traits were classified into 10 grades for analysis; grade $1<\mathrm{X}-2 \delta$ and grade $10>\mathrm{X}+2 \delta$, where the interval of every grade was $0.5 \delta$, and $\delta$ was the standard deviation.

\section{RESULTS}

\section{Identification of nematode species}

Based on morphology, the J2s used in this experiment were identified as M. incognita by Professor Zhang. Sequence-characterized amplified-region technology has been used widely to identify root-knot nematode species (Williamson et al., 1997; Zijlstra et al., 2000; Wu et al., 2005). This method is accurate and sensitive, and overcomes the shortcomings of traditional morphological identification (Wu et al., 2005). In this study, the sequence-characterized amplified-region method was used to identify which species of root-knot nematode were initially collected. A 500-bp fragment of Meloidogyne 28s rDNA was produced following amplification with Meloidogyne-universal MF/MR primers, and a 1000-bp fragment from M. incognita was produced following amplification with the Mi-F/Mi-R primers (Figure 1). This indicated that the root-knot nematodes collected were indeed Meloidogyne spp. To check whether these were species other than $M$. incognita, the Me-F/Me-R and Fjav/Rjav primers for M. enterolobii and M. javanica, respectively, were used to amplify the DNA. No band was observed on the resulting agarose gel; therefore, we could conclude that the root-knot nematodes collected did not include M. enterolobii or M. javanica, and were from a M. incognita population.

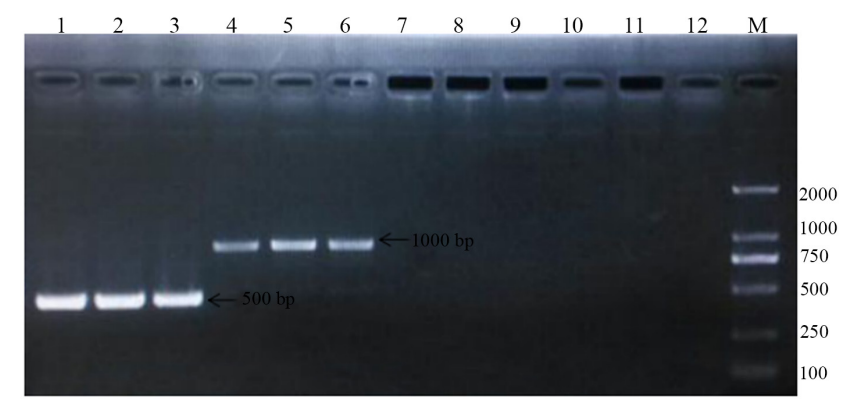

Figure 1. PCR products obtained using specific primers and DNA extracted from the collected root-knot nematodes. Lane M: DS2000 DNA marker; lanes 1-3: MF/MR; lanes 4-6: Mi-F/Mi-R; lanes 7-9: Me-F/Me-R; lanes 10-12: Fjav/Rjav.

\section{Identification of the resistance levels of 28 germplasms against $M$. incognita}

The growth indexes of PH, SD, AFPW, RFW, and TFW of the 28 seedlings inoculated by $M$. incognita differed. The growth indexes of all seedlings decreased following inoculation with M. incognita for 25 days, including Jinyan No.4, Jinchun No.4, and Commum CAT. The results showed that the M. incognita infestation had a significant effect on seedling growth; however, the decrease in the different growth indexes was not consistent, which indicated that 
infection with $M$. incognita on different organs of cucumber and rootstock seedlings was inhibited to varying degrees. The coefficients of variation for the growth indexes were: $\mathrm{PH}=3.39 \%$; $\mathrm{SD}=$ $3.86 \% ; \mathrm{AFPW}=4.93 \%$; RFW $=9.20 \%$; and $\mathrm{TFW}=5.85 \%$, which indicated that inoculation with M. incognita had a greater effect on the growth of roots than on the growth of aerial parts (Table 3 ).

Table 3. Effects of Meloidogyne incognita inoculation on the growth of 28 germplasm seedlings.

\begin{tabular}{|c|c|c|c|c|c|c|}
\hline \multirow[t]{2}{*}{ No. } & \multirow[t]{2}{*}{ Cultivar } & \multicolumn{5}{|c|}{ Relative growth rate (\%) } \\
\hline & & $\mathrm{PH}$ & SD & APFW & RFW & TFW \\
\hline 1 & No.14 & $98.85 \pm 1.04$ & $97.33 \pm 2.26$ & $91.56 \pm 1.92$ & $99.86 \pm 0.20$ & $95.18 \pm 1.26$ \\
\hline 2 & No.26 & $93.34 \pm 8.08$ & $98.18 \pm 0.59$ & $98.77 \pm 0.40$ & $94.26 \pm 2.29$ & $96.94 \pm 0.73$ \\
\hline 3 & Q24 & $97.28 \pm 1.12$ & $99.32 \pm 0.19$ & $98.08 \pm 1.36$ & $96.91 \pm 1.46$ & $97.62 \pm 0.25$ \\
\hline 4 & Q8 & $91.86 \pm 6.35$ & $95.75 \pm 4.84$ & $99.64 \pm 0.17$ & $98.75 \pm 0.20$ & $99.61 \pm 0.10$ \\
\hline 5 & Q16 & $97.69 \pm 1.13$ & $97.48 \pm 0.40$ & $94.89 \pm 4.18$ & $95.77 \pm 1.76$ & $98.04 \pm 2.01$ \\
\hline 6 & Commum CAT & $93.34 \pm 6.16$ & $88.69 \pm 10.24$ & $83.90 \pm 0.48$ & $67.30 \pm 4.20$ & $74.62 \pm 2.14$ \\
\hline 7 & Jinyou No.1 & $97.75 \pm 0.26$ & $94.00 \pm 3.23$ & $94.68 \pm 3.01$ & $96.98 \pm 2.37$ & $95.98 \pm 2.74$ \\
\hline 8 & Jinchun No.4 & $98.76 \pm 0.26$ & $96.31 \pm 1.12$ & $97.74 \pm 2.56$ & $90.40 \pm 2.14$ & $95.77 \pm 2.44$ \\
\hline 9 & Jinchun No.5 & $98.56 \pm 0.89$ & $90.93 \pm 2.36$ & $93.60 \pm 6.72$ & $91.88 \pm 7.86$ & $94.24 \pm 7.75$ \\
\hline 10 & Jinyan No.4 & $89.73 \pm 2.34$ & $95.69 \pm 2.15$ & $90.45 \pm 2.01$ & $94.48 \pm 6.02$ & $92.14 \pm 3.59$ \\
\hline 11 & Luyangxinsi & $98.08 \pm 1.32$ & $98.16 \pm 2.60$ & $89.26 \pm 1.27$ & $87.28 \pm 4.34$ & $94.44 \pm 5.99$ \\
\hline 12 & Baisite & $95.57 \pm 4.80$ & $97.98 \pm 0.10$ & $97.26 \pm 0.43$ & $98.83 \pm 0.33$ & $98.61 \pm 0.13$ \\
\hline 13 & Changchunmici & $99.75 \pm 0.10$ & $98.88 \pm 0.23$ & $97.96 \pm 1.73$ & $92.72 \pm 2.32$ & $95.96 \pm 1.82$ \\
\hline 14 & Laolaishao & $96.73 \pm 3.65$ & $96.90 \pm 1.59$ & $96.26 \pm 3.30$ & $92.57 \pm 4.90$ & $94.30 \pm 0.76$ \\
\hline 15 & Lisha & $89.05 \pm 10.55$ & $90.46 \pm 3.42$ & $92.56 \pm 6.43$ & $72.59 \pm 7.10$ & $82.14 \pm 0.71$ \\
\hline 16 & Zhongnong No.16 & $96.89 \pm 3.68$ & $94.95 \pm 3.76$ & $94.44 \pm 0.87$ & $89.37 \pm 5.01$ & $92.70 \pm 2.29$ \\
\hline 17 & Zhaibuwan & $92.71 \pm 9.47$ & $95.93 \pm 2.77$ & $80.63 \pm 11.45$ & $86.95 \pm 4.26$ & $83.33 \pm 7.95$ \\
\hline 18 & GaochanwangYapajia & $88.65 \pm 7.52$ & $96.66 \pm 1.58$ & $94.69 \pm 3.15$ & $93.59 \pm 4.83$ & $94.02 \pm 3.89$ \\
\hline 19 & Yanziru & $91.27 \pm 8.49$ & $93.62 \pm 0.92$ & $96.51 \pm 3.52$ & $82.17 \pm 12.22$ & $89.70 \pm 3.95$ \\
\hline 20 & Cuixiang No.6 & $94.87 \pm 3.87$ & $96.89 \pm 2.09$ & $93.72 \pm 2.22$ & $86.65 \pm 6.59$ & $94.17 \pm 0.10$ \\
\hline 21 & Liuyangbai & $94.95 \pm 1.00$ & $92.70 \pm 2.24$ & $89.95 \pm 1.65$ & $93.00 \pm 2.91$ & $91.68 \pm 0.93$ \\
\hline 22 & Qianglishi F1 & $95.44 \pm 3.76$ & $82.72 \pm 10.73$ & $95.06 \pm 0.90$ & $78.90 \pm 10.56$ & $90.53 \pm 2.32$ \\
\hline 23 & Ganfeng No.1 & $94.80 \pm 0.24$ & $92.86 \pm 0.40$ & $95.65 \pm 1.76$ & $79.35 \pm 3.07$ & $91.23 \pm 2.23$ \\
\hline 24 & Guozhen No.2 & $97.28 \pm 2.43$ & $96.64 \pm 1.32$ & $94.78 \pm 2.27$ & $79.31 \pm 4.88$ & $91.86 \pm 6.90$ \\
\hline 25 & Banzhen No.3 & $97.27 \pm 0.27$ & $99.14 \pm 0.87$ & $84.97 \pm 10.75$ & $95.41 \pm 2.59$ & $90.20 \pm 8.53$ \\
\hline 26 & Liangba & $90.38 \pm 1.86$ & $99.07 \pm 0.44$ & $91.67 \pm 0.39$ & $87.01 \pm 11.94$ & $90.10 \pm 3.84$ \\
\hline 27 & Huangzhen No.1 & $95.46 \pm 3.03$ & $96.67 \pm 1.12$ & $91.50 \pm 7.44$ & $81.58 \pm 12.41$ & $88.37 \pm 9.01$ \\
\hline 28 & Xiuli & $98.20 \pm 1.17$ & $96.41 \pm 1.39$ & $98.17 \pm 0.65$ & $93.04 \pm 6.15$ & $96.40 \pm 2.55$ \\
\hline \multicolumn{2}{|c|}{ Mean } & 95.16 & 95.37 & 93.51 & 89.18 & 92.50 \\
\hline \multicolumn{2}{|c|}{ Standard } & 3.22 & 3.68 & 4.61 & 8.20 & 5.41 \\
\hline \multicolumn{2}{|c|}{ Coefficient of Variation (\%) } & 3.39 & 3.86 & 4.93 & 9.20 & 5.85 \\
\hline
\end{tabular}

Data are mean \pm standard deviation of 10 individual seedlings for each germplasm in each experiment. The whole infection experiment was repeated at least three times; PH: plant height; SD: stem diameter; APFW: aerial part fresh weight; RFW: root fresh weight; TFW: total fresh weight.

A significant difference was found among the resistance indexes of the 28 germplasms (Table 4). GN, RIP, DI, and GI for the seven rootstocks were significantly lower than those for the 21 cucumber germplasms. Specifically, the 21 cucumber germplasms were classed as susceptible or highly susceptible to $M$. incognita, and most of the rootstocks had moderate resistance to $M$. incognita. Of the 21 germplasms, 11 were classed as highly susceptible, including Luyangxinsi, $\mathrm{Q}_{24}$, Laolaishao, Baisite, No.26, $\mathrm{Q}_{16}$, Changchunmici, Lisha, Zhaibuwan, Yapajia, and Yanziru, with an average DI of 4.79. Luyangxinsi and $\mathrm{Q}_{24}$ had the maximum DI of 5, as well as a much higher GN compared with the 11 highly susceptible germplasms (Figure 2A and B). The other 10 cucumber germplasms, and two of the rootstocks, were classed as susceptible to M. incognita, including Cuixiang No.6 and $\mathrm{Q}_{8}$ (Figure $2 \mathrm{C}$ and D). The average DI and GN of these groups were 3.67 and 53, respectively. The remaining five rootstocks, including Huangzhen No.1, Xiuli, Guozhen No.2, Banzhen No.3, and Ganfeng No.1, were classed as moderately resistance to $M$. incognita, in which Huangzhen No.1 and Xiulihad a lower GN than the other rootstocks (Figure 2E and F).

Genetics and Molecular Research 16 (2): gmr16029383 
Table 4. Effects of Meloidogyne incognita inoculation on resistance indexes of 28 germplasm seedlings.

\begin{tabular}{|c|c|c|c|c|c|c|}
\hline No. & Cultivar & GN(N) & RIP (\%) & GI & DI & Resistance \\
\hline 1 & No.14 & $73.50 \pm 1.73^{\mathrm{jk}}$ & 53 & 20.47 & 4.00 & Susceptible \\
\hline 2 & No.26 & $108.17 \pm 1.32^{\mathrm{fg}}$ & 81 & 33.25 & 4.89 & Highly susceptible \\
\hline 3 & $\mathrm{Q}_{24}$ & $137.72 \pm 10.42^{\mathrm{c}}$ & 94 & 41.55 & 5.00 & Highly susceptible \\
\hline 4 & Q8 & $81.67 \pm 4.59$ ij & 57 & 22.92 & 4.00 & Susceptible \\
\hline 5 & $\mathrm{Q}_{16}$ & $99.45 \pm 1.49^{\mathrm{gh}}$ & 59 & 51.06 & 4.33 & Highly susceptible \\
\hline 6 & Commum CAT & $89.75 \pm 7.15^{\mathrm{hi}}$ & 73 & 46.91 & 3.71 & Susceptible \\
\hline 7 & Jinyou No.1 & $19.40 \pm 2.48^{\mathrm{op}}$ & 20 & 12.94 & 3.00 & Susceptible \\
\hline 8 & Jinchun No.4 & $59.16 \pm 2.13^{\operatorname{lm}}$ & 35 & 65.74 & 3.94 & Susceptible \\
\hline 9 & Jinchun No.5 & $52.47 \pm 19.89^{\mathrm{m}}$ & 34 & 48.80 & 3.81 & Susceptible \\
\hline 10 & \begin{tabular}{|l|} 
Jinyan No.4 \\
\end{tabular} & $59.89 \pm 1.67^{1 \mathrm{~m}}$ & 32 & 19.77 & 4.00 & Susceptible \\
\hline 11 & Luyangxinsi & $122.67 \pm 5.69^{\mathrm{d}}$ & 90 & 40.48 & 5.00 & Highly susceptible \\
\hline$\overline{12}$ & Baisite & $109.00 \pm 1.02^{\mathrm{fg}}$ & 90 & 51.92 & 4.89 & Highly susceptible \\
\hline 13 & Changchunmici & $110.78 \pm 4.01^{\text {ef }}$ & 84 & 54.82 & 4.89 & Highly susceptible \\
\hline 14 & Laolaishao & $120.33 \pm 8.85^{\mathrm{de}}$ & 97 & 31.50 & 4.94 & Highly susceptible \\
\hline 15 & Lisha & $166.40 \pm 2.51^{\mathrm{a}}$ & 96 & 81.64 & 4.93 & Highly susceptible \\
\hline 16 & Zhongnong No.16 & $61.61 \pm 7.90^{\mathrm{lm}}$ & 32 & 52.13 & 4.00 & Susceptible \\
\hline 17 & Zhaibuwan & $171.67 \pm 3.17^{\mathrm{a}}$ & 90 & 66.08 & 4.60 & Highly susceptible \\
\hline 18 & Gaochanwang Yapajia & $90.86 \pm 3.88^{\mathrm{hi}}$ & 74 & 39.07 & 4.33 & Highly susceptible \\
\hline 19 & Yanziru & $154.48 \pm 6.55^{\mathrm{b}}$ & 94 & 63.85 & 4.87 & Highly susceptible \\
\hline 20 & Cuixiang No.6 & $64.53 \pm 11.00^{\mathrm{kl}}$ & 39 & 47.54 & 3.93 & Susceptible \\
\hline 21 & Liuyangbai & $29.94 \pm 2.99^{\mathrm{n}}$ & 26 & 12.37 & 3.47 & Susceptible \\
\hline 22 & Qianglishi F1 & $26.15 \pm 1.45^{\text {no }}$ & 23 & 18.91 & 3.07 & Susceptible \\
\hline 23 & Ganfeng No.1 & $13.35 \pm 1.86^{\mathrm{pq}}$ & 18 & 8.52 & 2.54 & Moderate resistance \\
\hline 24 & Guozhen No.2 & $18.22 \pm 1.29^{\mathrm{op}}$ & 22 & 12.46 & 2.94 & Moderate resistance \\
\hline 25 & Banzhen No.3 & $14.07 \pm 0.46^{\mathrm{pq}}$ & 17 & 13.74 & 2.60 & Moderate resistance \\
\hline 26 & Liangba & $19.29 \pm 1.84^{\mathrm{op}}$ & 22 & 16.05 & 3.13 & Susceptible \\
\hline 27 & Huangzhen No.1 & $5.51 \pm 0.32^{q}$ & 8 & 5.80 & 2.00 & Moderate resistance \\
\hline 28 & Xiuli & $9.61 \pm 1.27^{\mathrm{pq}}$ & 13 & 8.37 & 2.26 & Moderate resistance \\
\hline
\end{tabular}

Data are reported as means \pm standard deviation of 10 individual seedlings for each germplasm in each experiment. The whole infection experiment was repeated at least three times. Means within a column followed by the same letter are not significantly different according to Duncan's New Multiple Range Test at P $=0.05$; DI: 0-scale; where $0=$ no gall, $1=1-2$ galls, $2=3-10$ galls, $3=11-30$ galls, $4=31-100$ galls, and $5 \geq 100$ galls. Resistance of germplasms to root-knot nematodes was based on five levels, where $0=$ immune, $0-1.0=$ highly resistant, $1.0-2.0$ $=$ resistant, $2 \cdot 0-3 \cdot 0=$ moderately resistant, 3.0-4.0 $=$ susceptible, and $>4 \cdot 0=$ highly susceptible $(\mathrm{Li}$ and $\mathrm{Zhu}, 2005)$. GN: galls number; RIP: root infected percent; GI: gall index.

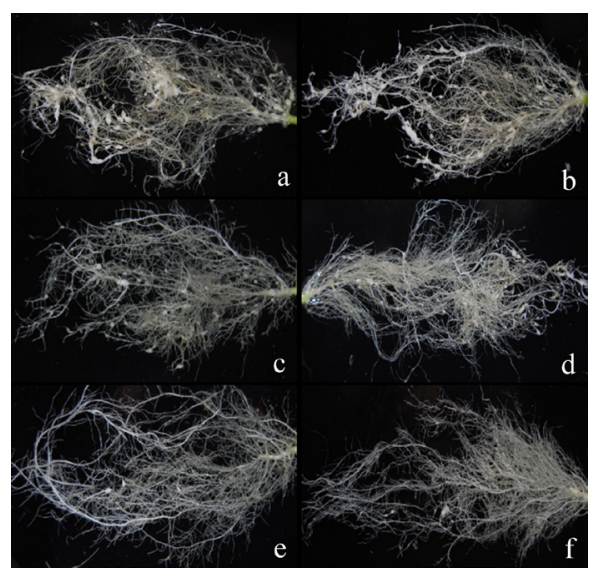

Figure 2. Root symptoms of six germplasms following inoculation with Meloidogyne incognita. a. Luyangxinsi; $\mathbf{b}$. $\mathrm{Q}_{24} ;$ c. Cuixiang No.6; d. $\mathrm{Q}_{8}$; e. Huangzhen No.1; f. Xiuli.

Genetics and Molecular Research 16 (2): gmr16029383 


\section{Cluster analysis}

The similarity coefficients of the 28 germplasms ranged from 0.02 to 1.00 . The dendrogram of the 28 germplasms constructed from the resistance indexes indicated that they were clustered into three main groups (Figure 3). The first group consisted of 10 cucumber germplasms, eight of which were classed as susceptible, including No.14, Jinchun No.4, Jinyan No.4, and Jinchun No.5, and two of which were classed as highly susceptible, including Q16 and Gaochanwang yapajia. The second group contained nine germplasms, including No.26, $\mathrm{Q}_{24}$, Luyangxinsi, and Laolaishao, which were all classed as highly susceptible. The third group included two cucumber germplasms and seven rootstocks, most of which were classed as moderately resistant, including Ganfeng No.1, Guozhen No.3, Banzhen No.3, and Xiuli, with the exception of Jinyou No.1, Liuyangbai, Qianglishi F1, and Liaba, which were classed as susceptible to $M$. incognita. The results of the cluster analysis were somewhat consistent with the classification of resistance indexes.

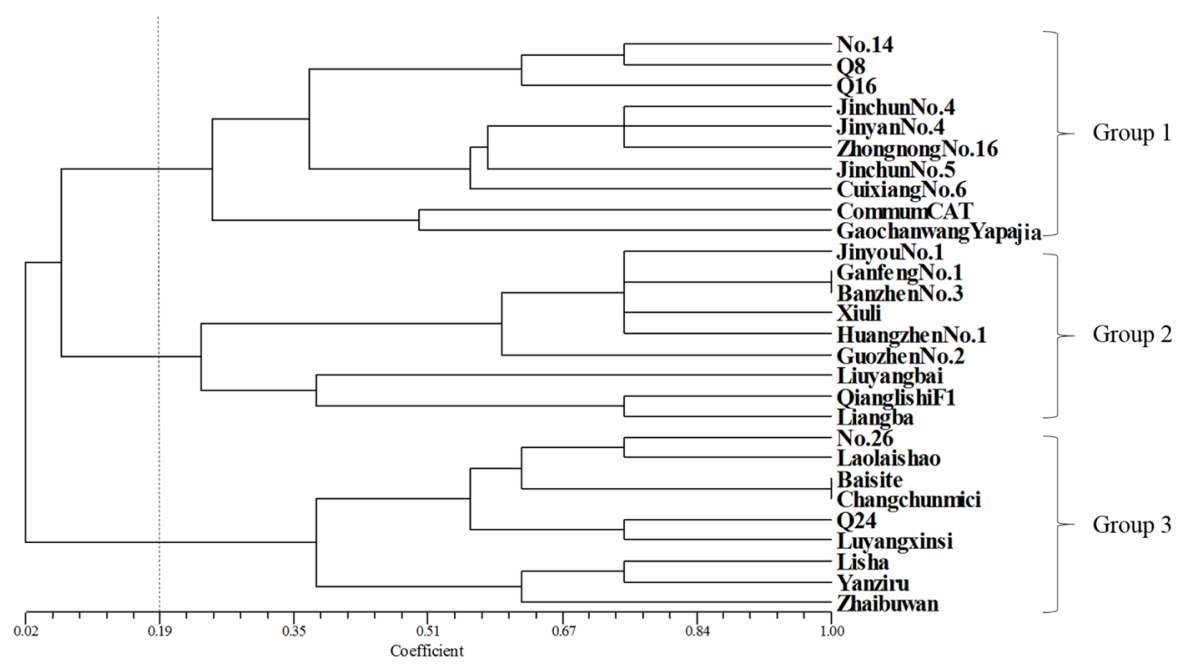

Figure 3. Unweighted pair group method with arithmetic mean dendrogram among the 28 germplasms based on Nei's coefficients. Three groups were defined based on combined markers: 1, 2, and 3. Group 1 includes 10 germplasms, Group 2 includes nine germplasms, and Group 3 includes nine germplasms.

\section{Principal component analysis (PCA)}

Grouping of different germplasms using PCA was based mainly on the first three principal coordinates, and the contribution of the first three principal coordinates were 39.93, 31.48 , and $10.69 \%$, respectively. $\mathrm{PC} 1$ was positively correlated with the relative growth rate of GI, RIP, DI, and RKN, while PC2 was positively correlated with PH, SD, AFPW, RFW, and TFW.

The scatter plot showing the distribution of 28 germplasms determined by $\mathrm{PC} 1$ and PC2, showed that the resistance indexes for the germplasms tended to increase with increasing values of $\mathrm{PC} 1$. The mean growth indexes of seedlings generally increased with increasing values of PC2. These data indicated that the 28 germplasms examined were partitioned into

Genetics and Molecular Research 16 (2): gmr16029383 
three distinct groups, and were consistent with the clustering results. The first group, including all rootstocks, Liuyangbai, and Jinyou No.1, was generally located on the left part of the PC1 axis. In addition to Xiuliand Jinyou No.1, this group had a low relative growth rate and low resistance indexes such as DI, GI, and GN. The second group was mostly positioned in the middle of the PC1 axis, and in the higher part of the PC2 axis. Jinchun No.4, Jinchun No.5, Cuixiang No.6, Zhongnong No.16, and four additional cucumber germplasms belonged to this group, which was characterized by relatively lower resistance indexes than the third group, and a higher relative growth rate than the first group. The third group was situated in the right part of the PC1 axis, which was composed of cucumber germplasm with high susceptibility to $M$. incognita. The relative growth rate of some germplasms of this group was high, and the other germplasms was low (Figure 4).

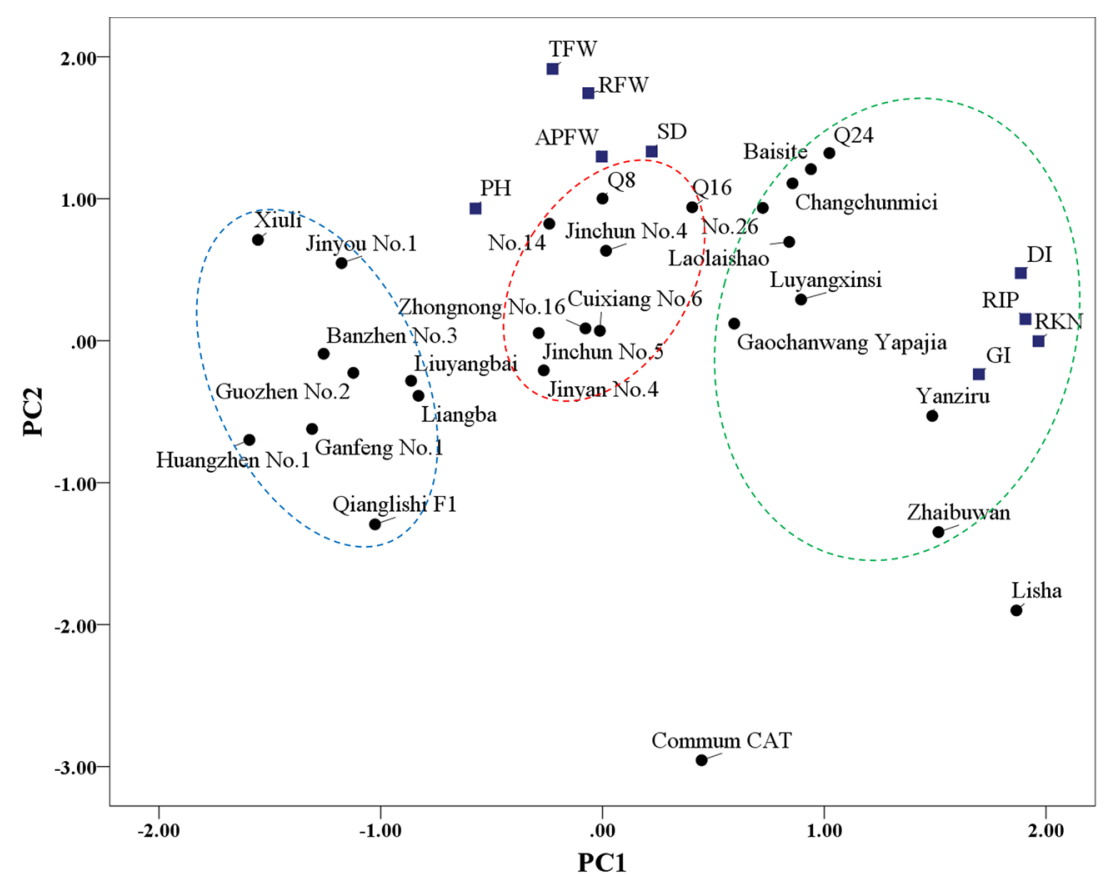

Figure 4. Scatter plot of the first two principal components based on the growth and resistance indexes of 28 germplasm. PH: plant height; SD: stem diameter; APFW: aerial part fresh weight; RFW: root fresh weight; TFW: total fresh weight; GN: galls number; RIP: root infected percent; GI: gall index.

\section{DISCUSSION}

Previous studies on the ability of Cucurbitaceae crops to resist root-knot nematodes have been carried out and can divided into different types. Jin et al. (2010) used galls index to evaluate the resistance of cucumber rootstocks and identified two resistance and susceptibility types. Shen et al. (2007) showed that based on disease index and population resistance evaluation standards, the cucumber and pumpkin rootstocks in their experiment could be divided into two types, moderate resistance and susceptibility. Thus, results obtained by evaluating different resistance indexes differ, making them difficult to compare. Because 
nematode infestation had different effects on different evaluation indexes, it was difficult to accurately assess plant resistance (Wang et al., 2013). The cluster analysis used in the present experiment was a comprehensive statistical analysis of multiple measurement indexes. It divided the subjects into categories according to the principle of similarity and eliminated the interference caused by artificially inconsistent standards.

In this experiment, all 21 cucumber germplasm seedlings exhibited little resistance to $M$. incognita, including the wild germplasm Commum CAT, which we expected would be more resistant. Most seedlings were classed as susceptible or highly susceptible to $M$. incognita, which was consistent with the findings of previous studies (Roberts, 1992). Aboulipour et al. (2011) reported that 15 cucumber cultivars in their sample were susceptible to M. javanica, and only two local cultivars were recognized as tolerant (Aboulipour et al., 2011). Walters et al. (1993) evaluated 884 cucumber (Cucumis sativus L.) and 24 horned cucumber (C. metuliferus Naud.) germplasms for their resistance to root-knot nematodes (Meloidogyne spp). They found that 24 of the C. metuliferus cultigens evaluated were resistant to all root-knot nematodes tested, and only 50 of the 884 C. sativus cultivars were somewhat resistant to $M$. arenaria and $M$. incognita.

Li et al. (2014) reported that resistance to root-knot nematodes was higher when the cucumber cultivar Cuilv was grafted to Huangzhen 3 and Xindongli rootstocks, with their disease indexes being reduced by 20.7 and $16.9 \%$ in spring, and 58.1 and $47.4 \%$ in autumn, respectively. Most rootstocks in the present experiment had higher resistance to $M$. incognita than the cucumber germplasms. The resistance indexes of Huangzhen No.1 were lowest among all rootstocks tested. Future experiments will aim to use Huangzhen No.1 as rootstocks for grafting experiments, and to determine the mechanism of grafting to alleviate root-knot nematode disease.

\section{Conflicts of interest}

The authors declare no conflicts of interest.

\section{ACKNOWLEDGMENTS}

We are grateful to the Shaanxi Science and Technology Program Project for provision of funds for this research under project \#2009K01-18 and \#2016NY-074.

\section{REFERENCES}

Aboulipour MR, Olia M, Fadaee AK and Kadivar M (2011). Reaction of some cucumber cultivars to root-knot nematode, Meloidogyne javanica. Iran. J. Plant Pathol. 47: 97-99.

Boiteux LS and Charchar JM (1996). Genetic resistance to root-knot nematode (Meloidogyne javanica) in eggplant (Solanum melongena). Plant Breed. 115: 198-200. http://dx.doi.org/10.1111/j.1439-0523.1996.tb00902.x

Cenis JL (1993). Identification of four major Meloidogyne spp. by random amplified polymorphic DNA (RAPD-PCR). Phytopathology 83: 76-76. http://dx.doi.org/10.1094/Phyto-83-76

Chen JF, Lin MS, Qian CT, Zhuang FY, et al. (2001). Identification of Meloidogyne incognita (Kofoid \& White) Chitwood resistance in Cucumis hystrix Chakr and the progenies of its interspecific hybrid with cucumber (C. sativus L.). $J$. Nanjing Agric. Univ 24: 21-24.

Dong W, Shi Y, Li R, Jiang R, et al. (2003). Species identification and occurrence investigation of vegetable root-knot nematodes under protected cultivation in Shandong province. J. Laiyang Agric. Coll. 21: 106-108.

Echeverrigaray S, Zacaria J and Beltrão R (2010). Nematicidal activity of monoterpenoids against the root-knot nematode

Genetics and Molecular Research 16 (2): gmr16029383 
Meloidogyne incognita. Phytopathology 100: 199-203. http://dx.doi.org/10.1094/PHYTO-100-2-0199

Escobar C, Barcala M, Cabrera J and Fenoll C (2015). Chapter one-overview of root-knot nematodes and giant cells. $A d v$. Bot. Res. 73: 1-32. http://dx.doi.org/10.1016/bs.abr.2015.01.001

Fassuliotis G and Rau GJ (1963). Evaluation of Cucumis spp. for resistance to the cotton root-knot nematode, Meloidogyne incognita acrita. Plant Dis. Rep 47: 809.

Hu MX, Zhuo K and Liao JL (2011). Multiplex PCR for the simultaneous identification and detection of Meloidogyne incognita, M. enterolobii, and M. javanica using DNA extracted directly from individual galls. Phytopathology 101: 1270-1277. http://dx.doi.org/10.1094/PHYTO-04-11-0095

Huang WK, Sun JH, Cui JK, Wang GF, et al. (2014). Efficacy evaluation of fungus Syncephalastrum racemosum and nematicide avermectin against the root-knot nematode Meloidogyne incognita on cucumber. PLoS One 9: e89717. http://dx.doi.org/10.1371/journal.pone.0089717

Huang WK, Cui JK, Liu SM, Kong LA, et al. (2016). Testing various biocontrol agents against the root-knot nematode (Meloidogyne incognita) in cucumber plants identifies a combination of Syncephalastrum racemosum and Paecilomyces lilacinus as being most effective. Biol. Control 92: 31-37. http://dx.doi.org/10.1016/j.biocontrol.2015.09.008

Huo YM, Xv YF, Wang CE, He QW, et al. (2008). Screening of Pumpkin Resistant to Meloidogyne incognita and CMV. Shandong Agric. Sci 8: 87-89.

Jia MQ and Wu GH (2011). Research review on cucumber root knot nematode disease. China Plant Prot. 31: 21-24.

Jin GL, Wang F, Huo YM, He QW, et al. (2010). Screening of Cucurbits rootstocks tolerant to root-knot nematodes. Shandong Agric. Sci 5: 89-91.

Li HY, Zhou JC, Zhang JX and Gu HL (2013). Screening on fungicides against cucumber root-knot nematode and control techniques. J. Anhui Agric. Sci 41: 9517-9518.

Li L, Wang PS, Zhou Y, Hao JJ, et al. (2014). Screening of cucumber rootstocks resistant to root-knot nematode. Shandong Agric. Sci 46: 110-112.

Liu B, Ren JJ, Zhang Y, An JB, et al. (2015). A new grafted rootstock against root-knot nematode for cucumber, melon, and watermelon. Agron. Sustain. Dev. 35: 251-259. http://dx.doi.org/10.1007/s13593-014-0234-5

Liu HX, Li SM, Luo YM, Luo LX, et al. (2014). Biological control of ralstonia wilt, phytophthora blight, Meloidogyne root-knot on bell pepper by the combination of Bacillus subtilis AR12, Bacillus subtilis SM21 and Chryseobacterium sp. R89. Eur. J. Plant Pathol. 139: 107-116. http://dx.doi.org/10.1007/s10658-013-0369-2

Li XX and Zhu DW (2005). Descriptors and data standard for cucumber (Cucumis staivus L.). China agriculture press, Beijing.

Lv J, Qi J, Shi Q, Shen D, et al. (2012). Genetic diversity and population structure of cucumber (Cucumis sativus L.). PLoS One 7: e46919. http://dx.doi.org/10.1371/journal.pone.0046919

Ma JH, Mao ZC, Li HX and Xie BY (2014). Resistance identification of Cucumis metuliferus to Meloidogyne incognita and characteristic analysis. Yuan Yi Xue Bao 41: 73-79.

Mao LG, Wang QX, Yan DD, Liu PF, et al. (2016). Application of the combination of 1, 3-dichloropropene and dimethyl disulfide by soil injection or chemigation: effects against soilborne pests in cucumber in China. J. Integr. Agric. 15: 145-152. http://dx.doi.org/10.1016/S2095-3119(15)61065-6

Mao ZC (2007). Isolated and analysis of resistance related genes in the interaction of root knot nematode and pepper. Master's thesis. North West Agriculture and Forestry University, Shaanxi.

Nei M (1972). Genetic distance between populations. Am. Nat. 106: 283-292. http://dx.doi.org/10.1086/282771

Pandey R, Kalra A, Gupta ML and Sharma P (2003). Phytonematodes: major pest of MAPs. In Proceedings of first National Interactive Meet on Medicinal and Aromatic Plants (Mathur AK, et al. eds.). CIMAP, Lucknow, India. 188-197.

Qiao K, Duan H, Wang H, Wang Y, et al. (2014). The efficacy of the reduced rates of 1, 3-D+ abamectin for control of Meloidogyne incognita in tomato production in China. Sci. Hortic. (Amsterdam) 178: 248-252. http://dx.doi. org/10.1016/j.scienta.2014.08.018

Roberts PA (1992). Current status of the availability, development, and use of host plant resistance to nematodes. $J$. Nematol. 24: 213-227.

Rohlf FJ (1998). On applications of geometric morphometrics to studies of ontogeny and phylogeny. Syst. Biol. 47: 147158, discussion 159-167. http://dx.doi.org/10.1080/106351598261094

Sebastian P, Schaefer H, Telford IR and Renner SS (2010). Cucumber (Cucumis sativus) and melon (C. melo) have numerous wild relatives in Asia and Australia, and the sister species of melon is from Australia. Proc. Natl. Acad. Sci. USA 107: 14269-14273. http://dx.doi.org/10.1073/pnas.1005338107

Shen D, Li XX, Feng LX, Wang HP, et al. (2007). Evaluation on resistance of Cucurbitaceae germplasm resources to rootknot nematode. J. Plant Genet. Resour 8: 340-342.

Genetics and Molecular Research 16 (2): gmr16029383 
Walters SA, Wehner TC and Barkel KR (1993). Root-knot nematode resistance in cucumber and horned cucumber. HortScience 28: 151-154.

Walters SA and Wehner TC (1997). 'Lucia', 'Manteo', and 'Shelby' root-knot nematode resistant cucumber inbred lines. HortScience 32: 1301-1303.

Wang C and Roberts PA (2006). A Fusarium wilt resistance gene in Gossypium barbadense and its effect on root-knot nematode-wilt disease complex. Phytopathology 96: 727-734.

Wang YY, Wei M, Shi W, Tian FM, et al. (2013). Resistance Evaluation of Rootstocks for Cucumber Grafting to Meloidogyne incognita. Tianjin Agric. Sci 19: 65-70.

Wang YY, Wei M, Shen Q, Li Y, et al. (2014). The physiological and biochemical response of cucumber rootstocks with different resistance against Meloidogyne incognita. J. Shandong Agric. Uni. (Nat. Sci. Ed.). 45: 522-528.

Williamson VM, Caswell-Chen EP, Westerdahl BB, Wu FF, et al. (1997). A PCR assay to identify and distinguish single juveniles of Meloidogyne hapla and M. chitwoodi. J. Nematol. 29: 9-15.

Winstead NN and Sasser JN (1956). Reaction of cucumber varieties to five root-knot nematodes (Meloidogyne spp.). Plant Dis. Rep. 40: 272-275.

Wu Y, Zhen JW, Shang HW and Hong WY (2005). Approaches and advances on the classification and identification of root knot nematode. Acta Agric. Zhejiangensis 17: 106-110.

Xi XM, Ba QJ, Zhang QP, Li YM, and Wang YC (2013). Control effect of different nematicides to the root-knot nematodes in greenhouse cucumber. Plant Prot. 3: 045.

Ye DY, Qian CT and Chen JF (2011). Screening and identification of cucumber-sour cucumber introgression lines resistant to the root-knot nematode Meloidogyne incognita. Yuan Yi Xue Bao 38: 2281-2288.

Zhang F, Zhang YL, Hong B, Li MY, et al. (2011). Species identification and distribution of root knot nematodes on greenhouse vegetables in Shaanxi Province. Acta Agric 20: 178-182.

Zijlstra C, Donkers-Venne DT and Fargette M (2000). Identification of Meloidogyne incognita, M. javanica and M. arenaria using sequence characterised amplified region (SCAR) based PCR assays. Nematology 28: 847-853. http:// dx.doi.org/10.1163/156854100750112798

Genetics and Molecular Research 16 (2): gmr16029383 